J. Goree, M. Ono, p. Colestock, R. Horton, D. McNeill, and H. Park

\title{
JULY 1985
}

\section{PLASMA PHYSICS

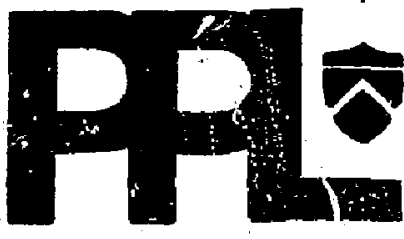

PRINCETON UNIVERSTTT

PRINCETON, NEW JERSEY

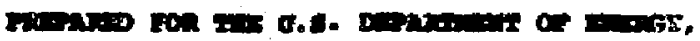

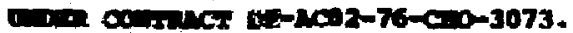




\title{
FAST MAVE CURRBAT DRIVS
}

\author{
J. Goree, M. Ono, P. Colestock, R. Horton ${ }^{\dagger}$, \\ D. Hckeill, and H. Fark \\ Plaswa Physicy Laboratory, Princeton University \\ Princeton. New Jersey 08544
}

\begin{abstract}
Fast wave current drive is demonstrated in the Princeton ACT-I toroide? device. The fast Alfuén wave, in the range of high ion-cyclotron harmonics, produced $40 \mathrm{~A}$ of current from $1 \mathrm{kr}$ of rf power coupled into the plasma by a fast wave loop antenra. This wave excites a steady current by damping on the energetic tail of the electron distribution Eunction in the same way as lower-hybrid current drive, except that fast wave current drive is appropriate for higher plasma densities.
\end{abstract}

PPPL-2238
DE85 015307

DISCLAIMER

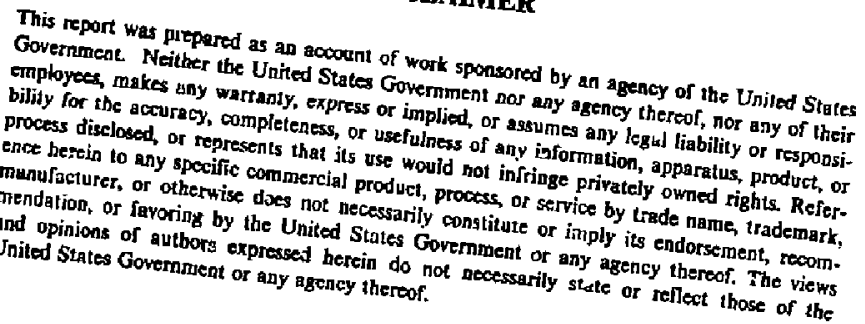

†Current address: Lawrence Livermore National Laboratory, Livernore, CA. 94550

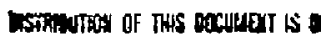


Radio frequency (If) current drive has become a familiar featurs of toroidal plasma experiments; 1 beginning in $1966^{\circ}$ with the observation of a steady current axcited by the ion-cyclotron wave in the C-Stellarator and more recently with the denongtration of lower-hybrid current drive (IHCD) in 1980 in the Princeton Advanced Concept Torue (ACT-I) toroidal device. 3 Recently, large currents mads by electron Iandau damping of the lower-hybrid wave have been sustained, and even started up, in tokamaks.4-7 For tokamak reactor operation, LHCD shows promise, but there remain problems such as a density iimit ${ }^{8}$ and gcattering by density fluctuations 9,10 that might be overcome by using other rf waves. The fast Alfven wave can interact with the superthermal tail of the electron distribution function to main;ain a current in much the game way as I. HCD.

Since the fast wave propagates at higher densitieg and has a longer wavelength perpendicular to the magnetic field, it may serve better than the lower-hybrid wave in a tokanak reactor. The lower-hybrid wave is ultirately iimited to plasmas less dense than the lower-hybrid resonarce density (see Fig. 1). Its short wavelength makes wave penetration more sensitive to the qualities of the plasma edge. This zetter reports zor the first time an observation of toroidal fast wave current arive (FWCD).

The experiment was cun on the ACP-I device, a torus with the following parameters: major radius $59 \mathrm{~cm}$, minor radius a $=7.6-8.6 \mathrm{~cm}$, toroidal field $B_{0}=4.5 \mathrm{kG}$, electron temperature $\leqslant 17 \mathrm{ev}$, and dengity $\overline{\mathrm{n}}_{\mathrm{e}}=3 \times 10^{12} \mathrm{~cm}^{-3}$. This machine's magnetic field has no poloidal component, and there is no toroidal electric field. Lines of force have a slight verticaI pitch. As they circle toroidally around the device, they make spirals that form vertical cylindrical surfaces. The lines are not closed; therefore, collisionless electron orbits are not confined indefinitely.

An intense 40-A, 400-eV linidirectional pulsed electron beam, injected into the plasma along the field, nakes a fast electron tail and ionizes the plasma as weIl. A lanthanum-hexabocide cathode inserted into the botton of the torus produces the bean, with the plasms serving as the anode. Numerical simulations by akuda et al., 11 indicate that the beam's contribution to the velocity distribution function takes a smooth negative slope, $f_{0}\left(v_{H}\right)(0$, and that this distribution extends to velocities much highex than the velocity of the electrons injected by the cathode. In the central portion of the plasma, 
the beam contains one percent or more of the electron density. Such a prominent feature in $f_{0}\left(v_{1}\right)$ is expected to be an ideal target for unidirectional danping of an $r F$ wave and for the prociuction of a unidirectional rf-driver current. In tact, a single element waveguide launcher was previously used for succestul LHOD using thid discharge. 12

For the present FWCD oxperinent, a single $140^{\circ}-t n m$ loop antenna excited the fast wave. This antenna is of the sawe type as those commonly used for fast wave ion cyclotron heating in tokamaks. It is covered with facaday shields to suppress electrostatic interaction with the plasma. A number of af diagnostics (magnetic loop probes, Langmuir probes, and far-infrared laser scattering "3) were used to detect the rf power in the plasma, tiereby identifying the fast wave and confirming that this mode was present eyerywere in the torus. The dispergion relation indicates that propagation requi res a sufficiently high wave frequency $w$, mass density $n_{i} m_{i}, B^{-1}$, and a. We therefore used a $\mathrm{He}^{+}$plasma, for its ion mass, making it possible to fit an eigenmode into the swall ACT-I cavity. The frequency; was $\omega=0\left(10 \Omega_{\mathrm{ci}}\right)$.

Fast wave current drive was observed by donitoring the signal from a Rogowski loop while the If power was pulsed on. The circulating current increased by $40 \mathrm{~A}$ when $1 \mathrm{~kW}$ of if power coupled into the plasma, as shown in Fig. 2. The following issues are examinet to ascertain that the current increase is caused by true F*CD.

The density declines during the application of cf prover, but that does not by itself promote a change in the total circulating current. As the dengity drops, the injected bean becomes less collisional; therefore, it circulates more times around the torus before its monentum expires in colligions. Meanwhile, the current leaving the cathode decreases, as required by the sheath condition. Taking these two effects into consideration, the total circulating current of the beam is proportional to the injected current divided by the collisional drag, and that ratio remains constant as the densi.ty changes.

Only rf-induced velocity space diffusion, i.e., true rf curre.tt drive, can shift the beam's distribution function to have more density at higher velocities and thereby augment the circulating current. Heating of the electrong lowers the plasm resistivity and would raise the ohmically driven vurrent if there any, but we operated the plasma without a toroidal 
electric field to avoid tinis complication. Without a change in the shape of the electron distribution tunction, a change in the beam cannot account for the okgerved increase in circulating current.

Modification of the plasma odge by the of does not make the curront increase, By sustaining a steady current for a Jong period of tims, we checked that the current increase is not produced by a monentary imbalance in particle fluxes when the if is turned on. As another test, we pusher the outroard side limiter in from its usual radius of $7.6 \mathrm{~cm}$, which matches the depth of the antenna, to a radius of $4.5 \mathrm{~cm}$; this caused little change in either the current increase or in the antenna loading.

The fast wave cutoff coincides with a threshold of the driven current. The throshold is seen when the plasma density is gradually lowered while holding all other parameters steady; tie extra current during if becones smailer and vanishes. The wave cutoff is determined from the magnitude of gignals from magnetic loop probes located far from the antenna. As the density is lowered, first there are a few broad peaks in the amplitude, suggesting the presence of various eigenmotes, and then the amplitude disappears. The densitieg at which the driven current and the probe gignals begin to vanish are plotted in Fig. 3 as a function of wave frequency. From the fast wave's dispersion relation, it is expected that the relationship of the inverse frequency of the wave cutoff, with density is linear. That dependence is seer in the wave data, and the driven current data coincides with it. From ali of these tests, we conclude that FWCD has been observed.

The current increase diminishes with neutral density in the partially ( $=50$ percent) ionized ACT-I plasma. Figlure 4 demonstrates this with the results of a neutral pressure scan. The electron density $\bar{n}_{e}$ was allowed to increase with the neutral pressure, while all other paraneters were held constant. Provided that the electron density is high enough to allow eigenmodes with the appropriate $k_{i}$ irto the jlasma, current arive is expected to be lesis at higher neutral densities and higher bulk electron densities, since fast electrons are collisional with the bulk electrons and neutrals.

An anisotropy is required to attain unidirectional current generation and not merely heating. In a tokamak, the fatvored way is the use of a phased array of antenne seructures that excites waves with a gingle direction of parallel phase velocity. All reported denonstrations of high-power Lfed in 
tokamaks have used this sethod, as will future FWCD experiments. The original stellarator rf current drive ${ }^{2}$ occurred becsuge of a structural anisotropy in the device, it had a magnetic beach (to heat ions) in one direction. Wayes were launched equally into the opposite direction, where only electrons could damp the we. In the present experiment, the unidirectional electron beam promotes the damping and velocity space diffusion required for $r$ curzent generation; the anisotropy in the target distribution function is responsible for the unidirectional current.

Comparing our experiment to LHCD uaing the same ACT-I device, 12 the efficiencies of FWCD and LHCD are comparable. We beileve that a detailed comparison of FWCD and LHCD efficiencies will be of interest in future tokaluak experiments. Ous experiment demonstrates that FWCD is physically posgible, but the efficiency cannot be extrapolated directly to a tokamak.

Performing FWCD and LHCD in the same tokamak promises to be an exciting suture experiment. An outstanding problem of explaining the success of IHCD is the question of how waves of high parallel phase velocity can excite a large current when there are virtually no electrons in the velodity gap between the antenna's spectrum of $w / k_{1}$ and the thermal bulk. Having current arive data for two different. saves, one might separate the effects of wave propagation and electron kinetics. The fast wave also offers a chance to exceed the LHCD density limit and to operate a tokamak without needless attention to the exact qualities of the enge plasma. This Letter reports a step in this direction in the development of steady-state current arive for tokamaks.

\section{ACKNOWLEDGMENTS}

The althors delightfully acknowledge discussions with $N$. Fisch, R. Motley, F. Skiff, and J. Stevens, and the use of codes written by J. Stevens and H.R. Tnompson. We thank W. Kineyko and J. Taylor for invaluable technicai assistance. This work was supported by U.S. Department of Energy Contract \# DE-ACO2-76-CHO-3073. 
REFERENCES

1H. Porkolab, IEEE Trans. Plasma Sni. PS-12, 103 (1984).

$Z_{S}$. Yoshikawa and H. Yamanoto, Phys, Fluids 9,1814 (1966).

${ }^{3}$ K.I. Fong, Phys. Rev. Lett. 45, 117 (1980).

${ }^{4} S$. Bernabei, C. Daughney, P. Efthimion, 4. Hooke, J. Hosea, F. Jobes, A. Martin, E. Mazzucato, E. Meservey, R. Motley, J. Stevens, S. von Goeler, and R. Wilson, Phys, Rev. Lett. 49, 1255 (1982).

5. Kubo, M. Nakanura, T. Cho, S. Nakao, T. Shimozuma, A. Ando, K. Ogura, T. Mekawa, Y. Termmichi, and S. Tanaka, Phys. Rev. Lett. 50, 1994 (1983).

6. Jobes, T. Stevens, R. Bell, 5. Bernabei, A. Cavallo, T.K. Chu, S. Cohen, B. Denne, P. Efthimion, E. Hinnov, H. Hooks, J. Hegea, E. Hazzucato, R. Mckilliams, R. Motley, S. Suckewer, G. Taylor, J. Timberlake, S. von Goeler, and R. Wilson, Phys. Rev. Lețt. 52, 1055 (1984).

7M. Poxkolab, J.J. Schuss, B Lloyd, Y. Takage, S. Texter, P. Bonoli, C. Fiore, R. Parker, and P. Pribyl, Phys. Rev. Lett. 53, 450 (1984).

G.G. Megrowe and F. Engelmann, Comments Plasma Phys, and Controlled Fusion 8 , $211(1984)$.

${ }^{9}$ E. Ott, Phys. Fluids 22, 1732 (1979).

10p.L. Andrews and F.w. Herkins, Phys. Fluids 26, 2537 (1983).

${ }^{11}$ H. Guda, R. Horton, $M_{*}$ Cno, and X.I. Fong, submitted to Fhys, Fluids.

12 R. Hortcn, Ph.D, thesis, Princeton University, 1985.

${ }^{13} \mathrm{~J}$. Goree, D.K. Mansfield, M. Ono, and K.I. Hong, J. Vac. Sci. Technol. A, Hay/June 1985 (in print). 


\section{FIGURE CRPTIONS}

Fig. 1. Dispersion relation of the fast and $\mathbf{s}$ low waves. The unbounded cold plasma dispersion relation solutions are shown for $B_{0}=4.47 \mathrm{kG}$, $f=18 \mathrm{Mtz}$, and $\mathrm{I}_{i}=4 \mathrm{AMU}$. This plet is made of two $\log -10 \mathrm{~g}$ plots joined togotherf one for positive, i.e., propagating valueg of $k_{\perp}^{2}$, and one for negative values. The upper horizonta! dashed line gives an estimate of the density requi.red to fit a half-wavelength across the dianeter of the ACT-I vessel. (The density actually required is less because rounded density profiles allow certain eigenmodes to propagate with less density.) The lower-hybrid resonance density is indicated by arrows.

Fig. 2. Circulating current $I_{R O G}$, and density $\bar{n}_{e}$, during the main discharge. The 18- $\mathrm{MHz}$ rf power is on for a duration of $5 \mathrm{msec}$ in alternate discinarges. The discharge without if is indicated by the dashed curve. The injected electron beam produces the current that circulates normally, and FWCD augments that current when rf power is applied. The discharges are highly repeatable.

Fig. 3. Fast wave cutoff and FwCD threshold densities. Their coincidence, and their identical scaling with frequency, show an interrelation of fast wave propagation and the current increase illugtrated in Fig. 2. A point between the two lowest identifiable peaks in a magnetic probe's amplitude is used for tho wave cutoff, and the half-maximun level of the current increase is used for the FWCD threshold. The difference in slopes are not physically ineaningful. Adjusting slightly the criteria for the cutoff or threshold could give the lines identical slopes. The neutral pressure was held congtant for this meagurement.

Fig. 4. Current drive scaling with neutral pressure. The increase in circulating current diminishes as the neutral fressure (and consequently the neutral density) increases, as shown by the open circles. The electron density follows the neutral density, as indicated by the top scale and the solid circles. The parameters 
were: $f=18 \mathrm{MHz}, B_{0}=4.6 \mathrm{~kg}$, and a larger vertical pitch was appiied to the field lines than for Fig. 2. 


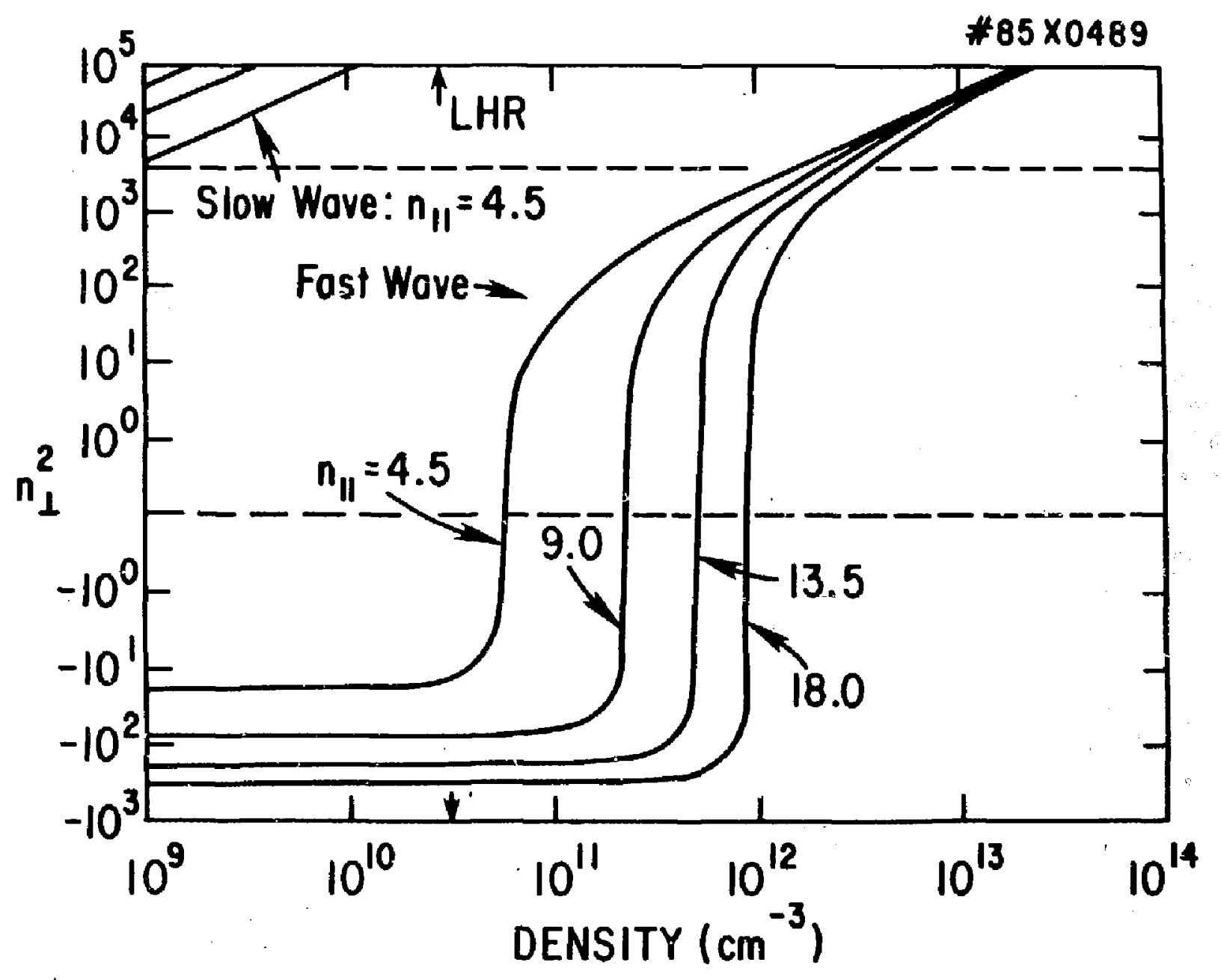

Fig. 1 

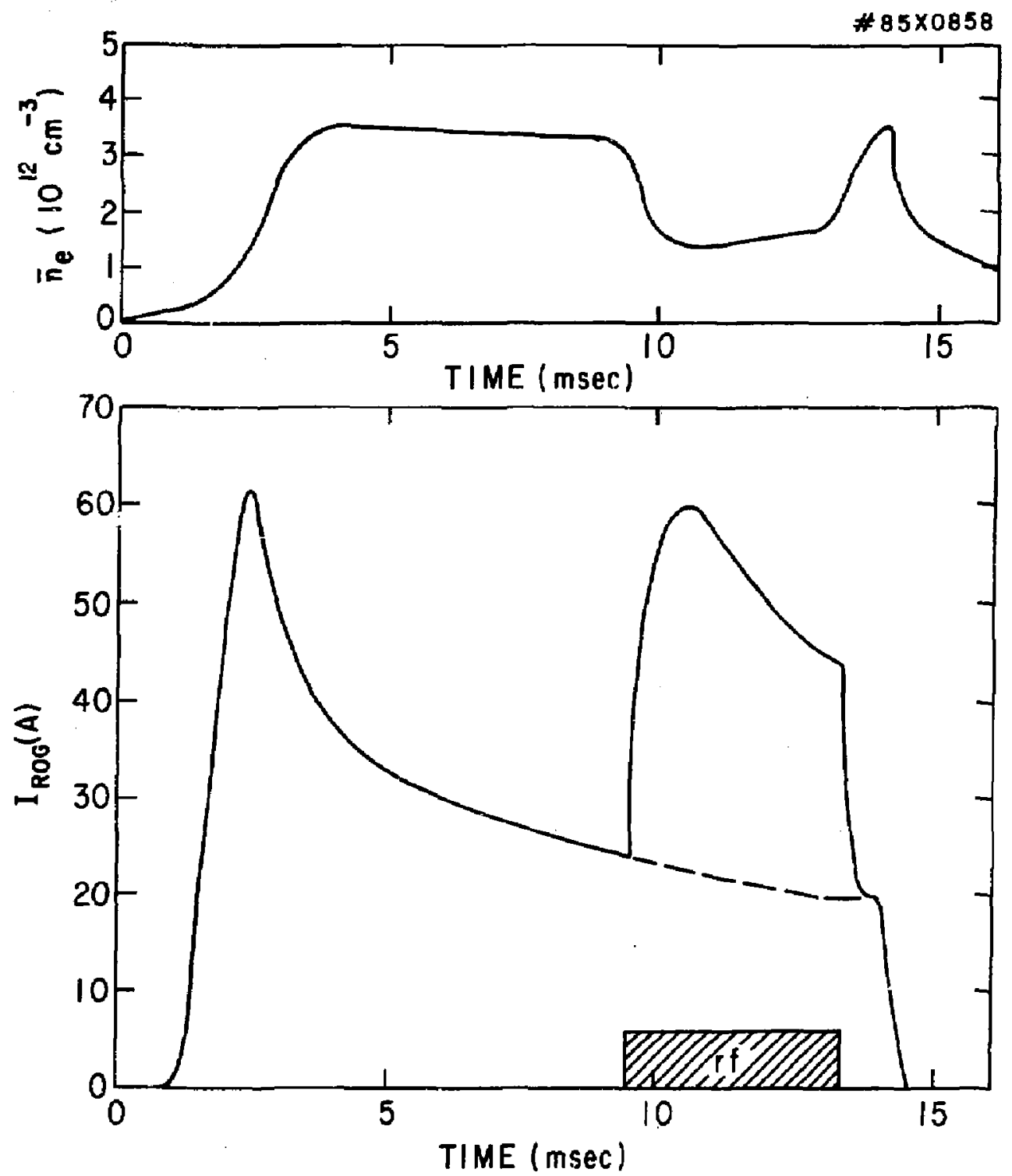

Fig. 2 


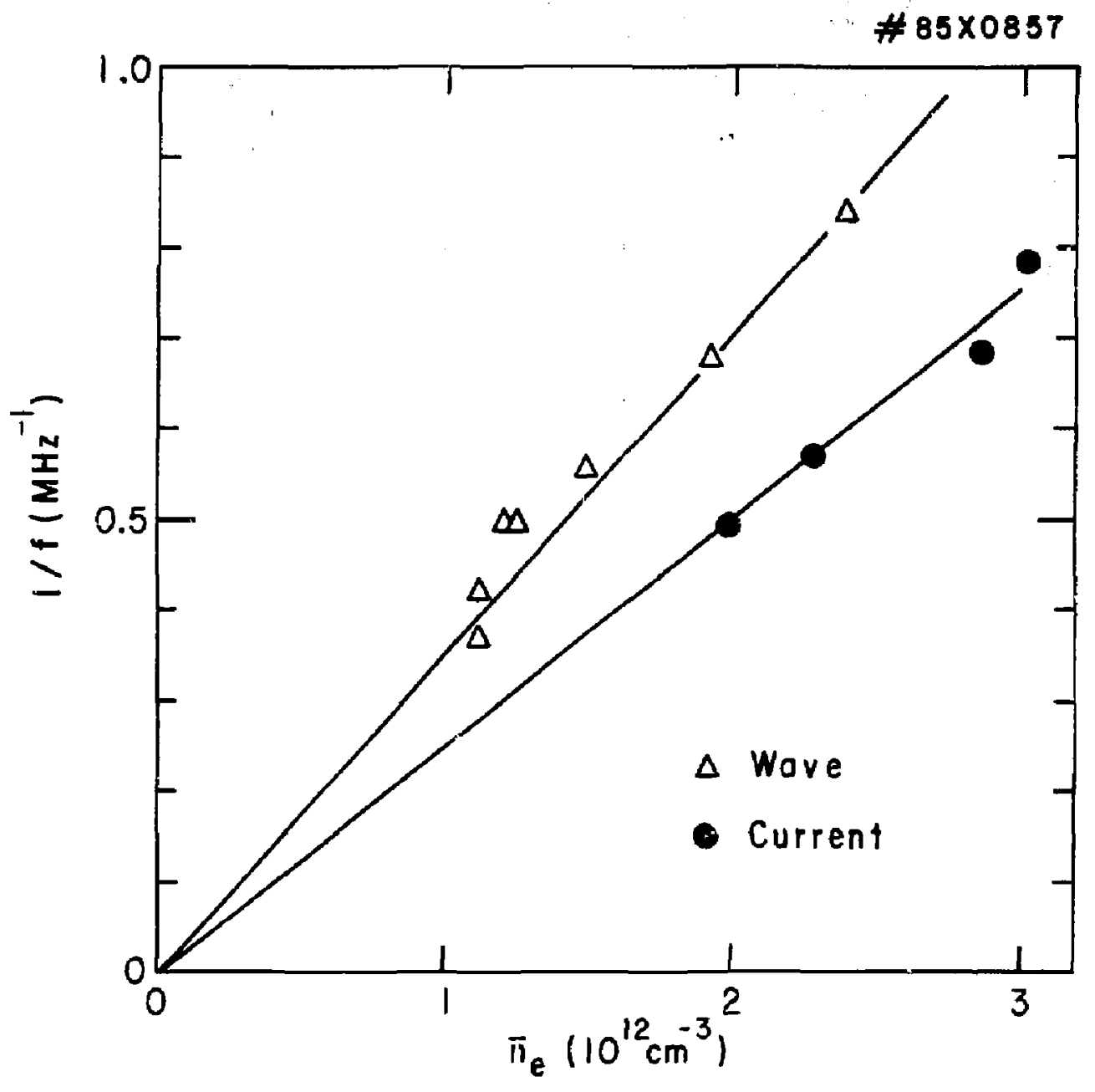

Fig. 3 
\#85X0895

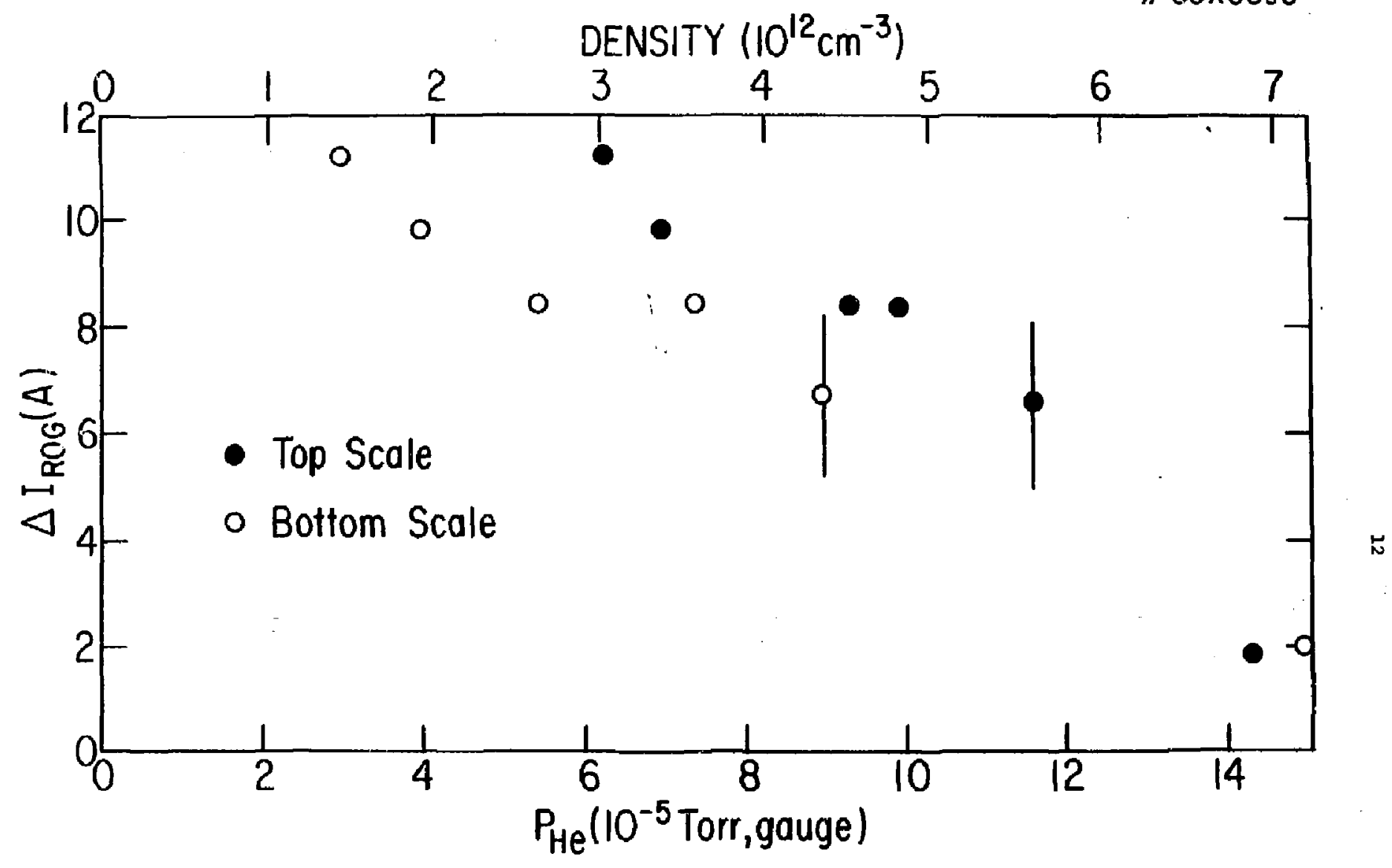

Fig. 4 


\section{BXIFRAPL DISTRIIUTION IN ADDITLAN TO UC-20}

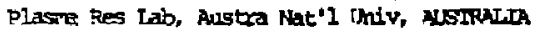
D. Etark J. Ealori, Oniv of Hollongorg, Austeat.A Prof. I.R. Janes, Elinders Univ., AUSTRALIA

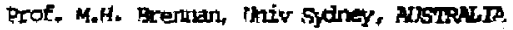

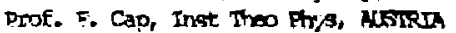
Prof, FIark Verteest, Inst theoretische Berank D. D. Palumb, og XII rusion Rrog, EstartM beole Royale Milftair, Lab de Ehys Plasmas, BEJGRM Dr. P.H. Sakarakt, Ohiv fataritul, ERATIL DF. C.R. Janes, oniv of AIberta, Cavan Prof. J. Telcham, univ of Montreal, Oumara DE. H,M. Skargard, univ of saskatcharan, Canod Prof. S.R. Sceenivasan, Universt.ty of Calgary, CANADA Prof. Tutor W. Johnston, INRS-Energie, CANaAA DT. Harres Barrant, Univ Fritish Columbia, Canada Dr. M.P. Bachynski, MPB Technologieg, Inc, PARaA Conalk River, wel Lab, Canas

Thengur Li, sh Inst thysics, Crma isbracy, Tsing tha University, ofm Librarian, Institute of Ptrylog, CHMA Inst plasta thys, Acadenia finica, Ormf Dr. Peter Lukac, Komenskeho Univ, cascostovaxIa The Libacian, Culham Liboratory, BNTWD Prof. Schatam, costratoire de kice, FRANCE J. Radet, CDN-BPS, ERANCE AM Dupes Iflbrary, HM Dupas Librery, ERMACT

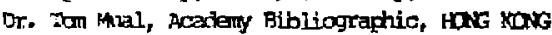
Preprint Library, Cent kes Inst Phys, HuNGAY Dr. S.K. Trehan, Parjah Uhiversity, INoia

Dr. Indra man Lail Das, Banaras Hinds thiv, INDTA

Tr. L.K. Chavda, South Gujarat Univ, INIA

Dr. R.K. Ohinjlani, vikran Univ. IRDIA

Tr. D. Dasgupta, Saha Inst, DOTA

Dr. P. Kaw, Ptyoical Research Lah, IDAA

Dr. Phillip Rosenalu, Israel Irst. Tech, ISRAFI.

Prof. 5. Cupeman, lel Aviv Uniwersity, ISRARL Prof. G. Rostagni, Univ Di Padoun, IMISY Librarian, Int'z Ctr Theo chys, IMUY Nos Clelta de galo, Asso FIRATO4-ENDA, IRLY Biblioteca, del ONR EIRATOM, ITLY DF, H, Yamato, Toshiba Res \& IMon, JALAN Direa. Dept Ig. Thikamak DEv. JMERI, JAPAF: PLof. Notwanki Inove, University of Tukya, JAFAN pesarch Inĩo Center, Nagoya thivergity, JAPAN Prof. Kyoji Nhohikawn, thily of Hiroghima, JAFAN Prof. Sigen Mori, JRERI, IAPAM ijbary, Kyoto Oniversity, JAPAN Prof. Ichiro kavaland, Niton thdv, JRPAN Pxof. Satoshi Itoh, Kysshe Ihiversity, JAPAN Dr. D.I. Ohoi, adv. Inat Sei \& Tech, KORSh Tech Info Division, Kaner, NCREM Bibliothesk, Fon-Ingt voor Plagma, NEIrFRTANOS
Prof. B.S. Liley, University of Mikato, NEN DEALAND Enof. J.M.c. Cabcal, Inst supertor Tect, BCRrutar DI. Detavian Petrus, ALI ORA Enitersity, RONANBP. Prof. M. A. Hellberg, University of Natal, So AFrtica Dr. Johan de trilliers, Plasma Ehysics, Nuor, 50 APRICA Fusion Div. Library, JN, SFAnN

Proc. Hans Gilheluson, Cralress univ Tech, 3 wDDFy [T. Lemart Stentio, Iniversity of UEA, SWIDEN Eibrary, Rojal Inst Tech, \$NEDE Centre de Recterctegm, Ecole Polytech Fad, \$HTLELAR: Dr. V.T. Tolok, Tharkoy Fhys Itech Ins, ISSR Dr, D.D. Ryrutor, Sibertan Acad Sci, USSR Dr. G.A. Eliseer, Kurchatou Instibute, ISSSR DT. V.A. Glukhikh, Inst Electro-Fhysical, USSR Institute Cen. Physics, USSRR Prof. Tut.h Boys, thiv College $N$ wales, WaLs Dr. Ko schindler, Fauhr Universitat, W. Germprry Muclear Res Dstab, Juizch Lta, W. GEavary Librarlan, Mex-Plandk Institut, w. GEPANY Bthliothel, Inst : Lastaforschumg, H. GPRANY Prof. R.K. Janes, Inst Fhys, Yuoostavia 